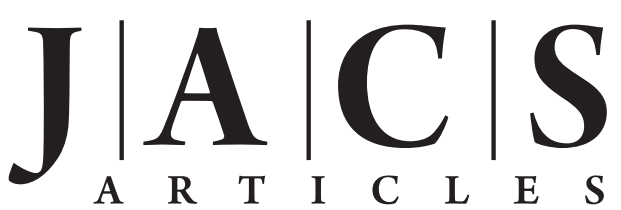

Published on Web 10/07/2010

\title{
Synthesis, Structure, and Dynamic Properties of Hybrid Organic-Inorganic Rotaxanes
}

\author{
Beatriz Ballesteros, ${ }^{\dagger}$ Thomas B. Faust, ${ }^{\ddagger}$ Chin-Fa Lee, ${ }^{\dagger}$ David A. Leigh, ${ }^{*, \dagger}$ \\ Christopher A. Muryn, ${ }^{\ddagger}$ Robin G. Pritchard, ${ }^{\ddagger}$ David Schultz, ${ }^{\dagger}$ Simon J. Teat, ${ }^{\S}$ \\ Grigore A. Timco, ${ }^{\ddagger}$ and Richard E. P. Winpenny, ${ }^{*, \neq}$ \\ School of Chemistry, University of Edinburgh, The King's Buildings, West Mains Road, \\ Edinburgh EH9 3JJ, United Kingdom, School of Chemistry and Photon Science Institute, \\ University of Manchester, Oxford Road, Manchester M13 9PL, United Kingdom, and \\ Advanced Light Source, Lawrence Berkeley Laboratory, 1 Cyclotron Road, \\ MS2-400, Berkeley, California 94720
}

Received August 18, 2010; E-mail: david.leigh@ed.ac.uk; richard.winpenny@man.ac.uk

\begin{abstract}
The synthesis and characterization of a series of hybrid organic-inorganic [2]rotaxanes is described. The ring components are heterometallic octa- $\left(\left[\mathrm{Cr}_{7} \mathrm{MF}_{8}\left(\mathrm{O}_{2} \mathrm{C}^{t} \mathrm{Bu}\right)_{16}\right] ; \mathrm{M}=\mathrm{Co}, \mathrm{Ni}, \mathrm{Fe}, \mathrm{Mn}, \mathrm{Cu}\right.$, $\mathrm{Zn}$, and $\mathrm{Cd}$ ) nuclear cages in which the metal centers are bridged by fluoride and pivalate $\left({ }^{\mathrm{t}} \mathrm{BuCO}_{2}{ }^{-}\right)$anions; the thread components feature dialkylammonium units that template the formation of the heterometallic rings about the axle to form the interlocked structures in up to $92 \%$ yield in conventional macrocyclization or one-pot 'stoppering-plus-macrocyclization' strategies. The presence in the reaction mixture of additives (secondary or tertiary amines or quaternary ammonium salts), and the nature of the stoppering groups $\left(3,5-{ }^{t} \mathrm{Bu}_{2} \mathrm{C}_{6} \mathrm{H}_{3} \mathrm{CO}_{2}-\right.$ or $\left.{ }^{\mathrm{B}} \mathrm{BuCONH}-\right)$, can have a significant effect on the rotaxane yield. The X-ray crystal structures of 11 different [2]rotaxanes, a pseudorotaxane, and a two-station molecular shuttle show two distinct types of intercomponent hydrogen bond motifs between the ammonium groups of the organic thread and the fluoride groups of the inorganic ring. The different hydrogen bonding motifs account for the very different rates of dynamics observed for the heterometallic ring on the thread (shuttling slow; rotation fast).
\end{abstract}

\section{Introduction}

Although metal ions have been extensively used to template the assembly of catenanes, rotaxanes, knots, and links ${ }^{1}$ and form an integral part of the components of some interlocked molecules, ${ }^{2}$ there are few examples ${ }^{3}$ of the mechanical linking of organic and inorganic components at the molecular level. We recently described the synthesis of rotaxanes in which an essentially inorganic wheel (featuring seven $\mathrm{Cr}$ (III) trications and one $\mathrm{Co}(\mathrm{II})$ dication or ten $\mathrm{Cr}$ (III) trications and two $\mathrm{Cu}$ (II) dications) is assembled around a linear organic axle terminated with bulky $3,5-{ }^{t} \mathrm{Bu}_{2} \mathrm{C}_{6} \mathrm{H}_{3} \mathrm{CO}_{2}-$ 'stoppers'. ${ }^{4}$ Here we report on the synthesis and solid state structures of novel hybrid organic-inorganic [2] rotaxanes based on $\mathrm{Ni}(\mathrm{II}), \mathrm{Fe}(\mathrm{II}), \mathrm{Mn}(\mathrm{II})$, $\mathrm{Cu}(\mathrm{II}), \mathrm{Zn}(\mathrm{II})$, and $\mathrm{Cd}(\mathrm{II})$ as the divalent metal ion, together with an investigation of the factors (nature of the stopper groups and the use of amine/ammonium additives in the rotaxane-

\footnotetext{
¿ University of Edinburgh.

$\doteqdot$ University of Manchester.

$\S$ Advanced Light Source.

(1) For reviews on interlocked molecules assembled about transition metal templates, see: (a) Sauvage, J.-P.; Dietrich-Buchecker, C. Molecular Catenanes, Rotaxanes and Knots; Wiley-VCH: Weinheim, Germany, 1999. (b) Hubin, T. J.; Busch, D. H. Coord. Chem. Rev. 2000, 200202, 5-52. (c) Collin, J.-P.; Dietrich-Buchecker, C.; Gaviña, P.; Jimenez-Molero, M. C.; Sauvage, J.-P. Acc. Chem. Res. 2001, 34, 477487. (d) Menon, S. K.; Guha, T. B.; Agrawal, Y. K. Rev. Inorg. Chem 2004, 24, 97-133. (e) Cantrill, S. J.; Chichak, K. S.; Peters, A. J. Stoddart, J. F. Acc. Chem. Res. 2005, 38, 1-9. (f) Crowley, J. D.; Goldup, S. M.; Lee, A.-L.; Leigh, D. A.; McBurney, R. T. Chem Soc. Rev. 2009, 38, 1530-1541.
}

forming reaction) that can significantly affect the rotaxane yield. The hybrid structures have dynamic properties that hitherto have been the preserve of wholly organic molecules, such as the large amplitude thermal movement of the macrocycle up and down the axle (a molecular shuttle ${ }^{5}$ ), a motion of interest for synthetic molecular machine systems. ${ }^{6}$

The design of the hybrid organic-inorganic rotaxane system lies in the observation ${ }^{7}$ that the formation of heterometallic rings $^{8}$ of various shapes and sizes, containing seven or more trivalent $\mathrm{Cr}(\mathrm{III})$ ions and one or two divalent metal ions (typically $\mathrm{Ni}(\mathrm{II}), \mathrm{Co}(\mathrm{II}), \mathrm{Fe}(\mathrm{II}), \mathrm{Mn}(\mathrm{II})$, or $\mathrm{Cu}(\mathrm{II})$ ) bridged by multiple fluoride and alkyl or aryl carboxylate anions, is templated by various organic cations, ${ }^{7 \mathrm{~d}}$ including imidazolium, ${ }^{7 \mathrm{c}}$ $N$-alkylimidazolium, ${ }^{7 \mathrm{c}}$ and primary $^{7 \mathrm{~b}}$ and secondary ${ }^{7 \mathrm{a}}$ ammonium groups. The magnetic characteristics of these heterometallic rings have led to their investigation as potential qubits for quantum information processing. ${ }^{9}$ A key question for this proposed application is how to link qubits to entangle spins without causing decoherence; mechanically interlocked structures may allow the manipulation of weak through-space interactions between such components in a manner that is difficult to achieve with conventional molecular architectures. Dialkylammonium salts have previously been used to direct the assembly of rotaxanes based on crown ethers, ${ }^{10}$ cucurbituril, ${ }^{11}$ and cyclic peptides, ${ }^{12}$ and so it seemed plausible that they might also template the formation of rotaxanes featuring heterometallic rings. 
Scheme 1. Synthesis of [2]Rotaxanes with $3,5-{ }^{-} \mathrm{Bu}_{2} \mathrm{C}_{6} \mathrm{H}_{3} \mathrm{CO}_{2}-$ Stoppers, $\mathbf{2 a}-\mathbf{e}^{a, b}$

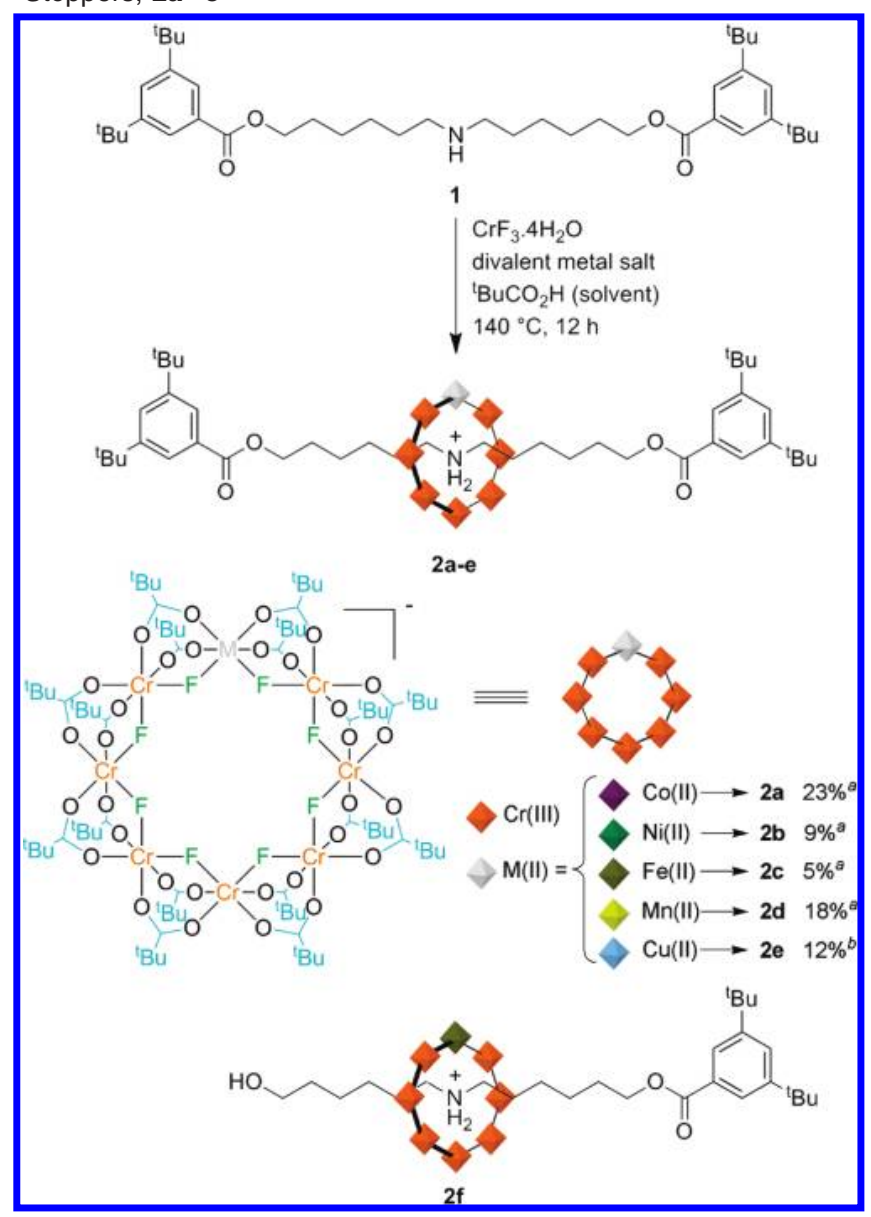

${ }^{a}$ Reaction conditions: Thread 1 ( 1 equiv), $\mathrm{CrF}_{3} \cdot 4 \mathrm{H}_{2} \mathrm{O}$ (5 equiv), divalent metal salt $\left(\left[\mathrm{Co}\left(\mathrm{OH}_{2}\right)\left(\mathrm{O}_{2} \mathrm{CCMe}_{3}\right)_{4}\left(\mathrm{HO}_{2} \mathrm{CCMe}_{3}\right)_{4}\right],\left[2 \mathrm{NiCO}_{3} \cdot 3 \mathrm{Ni}(\mathrm{OH})_{2} \cdot 4 \mathrm{H}_{2} \mathrm{O}\right]\right.$, $\mathrm{FeCl}_{2} \cdot 4 \mathrm{H}_{2} \mathrm{O}, \mathrm{MnCl}_{2} \cdot 4 \mathrm{H}_{2} \mathrm{O}$ or $\left.\mathrm{CuCO}_{3} \cdot \mathrm{Cu}(\mathrm{OH})_{2}\right)$ (1 equiv), pivalic acid (50-60 equiv), $140^{\circ} \mathrm{C}, 12 \mathrm{~h}$. Isolated yields are based on $\mathrm{Cr}(\mathrm{IIII})$ as the limiting reagent. Changing the ester-linked aryl stoppers of the threads to tert-butylamide groups increases the isolated [2]rotaxane yields to $42-92 \%$ (see Scheme 3); the use of additives and the optimization of the reaction conditions increased the yield of rotaxane 2a up to $70 \%$ (see Scheme 4). ${ }^{b} 1$ equiv of tetraethylammonium chloride was added.

Synthesis and Characterization of $3,5-{ }^{t} \mathrm{Bu}_{2} \mathrm{C}_{6} \mathrm{H}_{3} \mathrm{CO}_{2}$-Stoppered [2]Rotaxanes. Thread $\mathbf{1}$ features a secondary amine group separated by a six methylene group spacer from bulky 3,5${ }^{t} \mathrm{Bu}_{2} \mathrm{C}_{6} \mathrm{H}_{3} \mathrm{CO}_{2}-$ ester groups at each end of the axle to prevent dethreading of the heterometallic ring intended to be assembled around the ammonium template. The thread was reacted ${ }^{7 \mathrm{a}}$ with a 5:1 molar ratio of chromium(III) fluoride $\left(\mathrm{CrF}_{3} \cdot 4 \mathrm{H}_{2} \mathrm{O}\right)$ and a range of different divalent metal salts $\left(\left[\mathrm{CO}_{2}\left(\mathrm{H}_{2} \mathrm{O}\right)\left({ }^{t} \mathrm{BuCO}_{2}\right)_{4}\right.\right.$ $\left.\left({ }^{t} \mathrm{BuCO}_{2} \mathrm{H}\right)_{4}\right],\left[2 \mathrm{NiCO}_{3} \cdot 3 \mathrm{Ni}(\mathrm{OH})_{2} \cdot 4 \mathrm{H}_{2} \mathrm{O}\right], \mathrm{FeCl}_{2} \cdot 4 \mathrm{H}_{2} \mathrm{O}, \mathrm{MnCl}_{2}$ • $4 \mathrm{H}_{2} \mathrm{O}$, or $\mathrm{CuCO}_{3} \cdot \mathrm{Cu}(\mathrm{OH})_{2}$ ), with pivalic acid as the solvent, at $140{ }^{\circ} \mathrm{C}$ for $12 \mathrm{~h}$ (Scheme 1). The corresponding [2] rotaxanes $\mathbf{2 a}-\mathbf{d}$ were produced in $5-23 \%$ yield, which is rather efficient for what is essentially a 33 component assembly process (each metal-ligand bond is, in principle, dynamic under the reaction conditions). The $\mathrm{Cr}_{7} \mathrm{Fe}$-rotaxane $2 \mathrm{c}$ proved to be rather unstable in solution and partially decomposed during the purification and crystallization processes. $\mathrm{A} \mathrm{Cr}_{7} \mathrm{Fe}$-pseudorotaxane, $2 \mathbf{f}$, in which one of the stopper groups had been hydrolyzed was also isolated from the rotaxane-forming reaction. Using these conditions with $\mathrm{Cu}$ (II) salts produced a complex mixture of products from which no [2] rotaxane could be isolated. However, performing the reaction in the presence of 1 equiv of $\mathrm{Et}_{4} \mathrm{NCl}$ (an additive found to increase rotaxane yield, vide infra) simplified the product distribution (and probably increased the amount of rotaxane formed) enabling the $\mathrm{Cr}_{7} \mathrm{Cu}$-[2] rotaxane $2 \mathrm{e}$ to be prepared in $12 \%$ yield.

In all these rotaxane-forming reactions the octametallic ring is a monoanion (24 monoanionic ligands -8 fluorides and 16 pivalate groups - bound to seven $\mathrm{Cr}$ (III) trications and one dication) whose charge is balanced by the ammonium cation formed by protonation of the thread. Thus the rotaxanes are overall neutral molecules, and as the 'oily' tert-butyl groups of the pivalates form the outer-coating of the inorganic ring, they generally exhibit good solubility in nonpolar organic solvents $\left(\mathrm{CH}_{2} \mathrm{Cl}_{2}, \mathrm{CHCl}_{3}\right.$, toluene, $\mathrm{Et}_{2} \mathrm{O}$, etc. $)$. The synthesis has several possible variables, including the nature of the trivalent metal

(2) For examples of interlocked molecules with transition metals as structural elements, see: (a) Ogino, H. J. Am. Chem. Soc. 1981, 103, 1303-1304. (b) Fujita, M.; Ibukuro, F.; Hagihara, H.; Ogura, K. Nature 1994, 367, 720-723. (c) Fujita, M.; Ibukuro, F.; Yamaguchi, K.; Ogura, K. J. Am. Chem. Soc. 1995, 117, 4175-4176. (d) Piguet, C.; Bernardinelli, G.; Williams, A. F.; Bocquet, B. Angew. Chem., Int. Ed. Engl. 1995, 34, 582-584. (e) Mingos, D. M. P.; Yau, J.; Menzer, S.; Williams, D. J. Angew. Chem.. Int. Ed. Engl. 1995, 34, 18941895. (f) Fujita, M.; Ogura, K. Coord. Chem. Rev. 1996, 148, 249264. (g) Fujita, M.; Ibukuro, F.; Seki, H.; Kamo, O.; Imanari, M.; Ogura, K. J. Am. Chem. Soc. 1996, 118, 899-900. (h) Whang, D.; Park, K.-M.; Heo, J.; Kim, K. J. Am. Chem. Soc. 1998, 120, 48994900. (i) Try, A. C.; Harding, M. M.; Hamilton, D. G.; Sanders, J. K. M. J. Chem. Soc., Chem. Commun. 1998, 723-724. (j) Fujita, M.; Fujita, N.; Ogura, K.; Yamaguchi, K. Nature 1999, 400, 52-55. (k) Fujita, M. Acc. Chem. Res. 1999, 32, 53-61. (1) Jeong, K. S.; Choi, J. S.; Chang, S. Y.; Chang, H. Y. Angew. Chem., Int. Ed. 2000, 39, 1692-1695. (m) Padilla-Tosta, M. E.; Fox, O. D.; Drew, M. G. B.; Beer, P. D. Angew. Chem., Int. Ed. 2001, 40, 4235-4239. (n) Park, K.-M.; Kim, S.-Y.; Heo, J.; Whang, D.; Sakamoto, S.; Yamaguchi, K.; Kim, K. J. Am. Chem. Soc. 2002, 124, 2140-2147. (o) Kim, K. Chem. Soc. Rev. 2002, 31, 96-107. (p) McArdle, C. P.; Irwin, M. J.; Jennings, M. C.; Vittal, J. J.; Puddephatt, R. J. Chem.-Eur. J. 2002, 8, 723-734. (q) McArdle, C. P.; Van, S.; Jennings, M. C.; Puddephatt, R. J. J. Am. Chem. Soc. 2002, 124, 3959-3965. (r) Dietrich-Buchecker, C.; Colasson, B.; Fujita, M.; Hori, A.; Geum, N.; Sakamoto, S.; Yamaguchi, K.; Sauvage, J.-P. J. Am. Chem. Soc. 2003, 125, 57175725. (s) Burchell, T. J.; Eisler, D. J.; Puddephatt, R. J. Dalton Trans. 2005, 268-272. (t) Chang, S.-Y.; Jeong, K.-S. J. Org. Chem. 2003, 68, 4014-4019. (u) Liu, Y.; Song, S.-H.; Chen, Y.; Zhao, Y.-L.; Yang, Y.-W. Chem. Commun. 2005, 1702-1704. (v) Suzaki, Y.; Taira, T.; Osakada, K.; Horie, M. Dalton Trans. 2008, 4823-4833. (w) Wong, W. W. H.; Cookson, J.; Evans, E. A. L.; McInnes, E. J. L.; Wolowska, J.; Maher, J. P.; Bishop, P.; Beer, P. D. Chem. Commun. 2005, 22142216. (x) Habermehl, N. C.; Jennings, M. C.; McArdle, C. P.; Mohr, F.; Puddephatt, R. J. Organometallics 2005, 24, 5004-5014. (y) Fujita, M.; Tominaga, M.; Hori, A.; Therrien, B. Acc. Chem. Res. 2005, 38, 369-378. (z) Blanco, V.; Chas, M.; Abella, D.; Peinador, C.; Quintela, J. M. J. Am. Chem. Soc. 2007, 129, 13978-13986. (aa) Yang, H.-B.; Ghosh, K.; Northrop, B. H.; Zheng, Y.-R.; Lyndon, M. M.; Muddiman, D. C.; Stang, P. J. J. Am. Chem. Soc. 2007, 129, 14187-14189. (bb) Westcott, A.; Fisher, J.; Harding, L. P.; Rizkallah, P.; Hardie, M. J. J. Am. Chem. Soc. 2008, 130, 2950-2951. (cc) Ghosh, K.; Yang, H.B.; Northrop, B. H.; Lyndon, M. M.; Zheng, Y.-R.; Muddiman, D. C.; Stang, P. J. J. Am. Chem. Soc. 2008, 130, 5320-5334. (dd) Ronson, T. K.; Fisher, J.; Harding, L. P.; Rizkallah, P. J.; Warren, J. E.; Hardie, M. J. Nature Chem. 2009, 1, 212-216.

(3) For metal-organic rotaxane frameworks (MORFs), one-, two-, and three-dimensional arrays of organic rotaxanes linked by metal coordination bonds, see: (a) Loeb, S. J. Chem. Commun. 2005, 15111518. (b) For catenanes incorporated into a metal-organic framework (MOF), see: Li, Q.; Zhang, W.; Miljanic, O. Š.; Knobler, C. B.; Stoddart, J. F.; Yaghi, O. M. Chem. Commun. 2010, 46, 380-382. (c) Li, Q.; Sue, C.-H.; Basu, S.; Shveyd, A. K.; Zhang, W.; Barin, G.; Fang, L.; Sarjeant, A. A.; Stoddart, J. F.; Yaghi, O. M. Angew. Chem., Int. Ed 2010, 49, 6751-6755. For interpenetrated nets of coordination polymers, see: (d) Batten, S. R.; Robson, R. Angew. Chem., Int. Ed. 1998, 37, 1460-1494. For polypseudorotaxanes featuring polyoxomolybdate clusters that encircle $p$-phenylenebutadiynylene polymer chains, see: (e) Alam, M. A.; Kim, Y.-S.; Ogawa, S.; Tsuda, A.; Ishii, N.; Aida, T. Angew. Chem., Int. Ed. 2008, 47, 2070-2073. 
ion, the divalent metal ion, the carboxylate, the fluoride, and the amine, leading, in principle, to a wide variety of differently functionalized rotaxanes. ${ }^{13}$ In this paper we probe the effect on structure and yield of changing the divalent metal ion, the nature of the rotaxane end-groups, and the addition of amine and ammonium additives to the reaction mixture.

X-ray crystal structures of four of the [2] rotaxanes $\mathbf{2 a}, \mathbf{2} \mathbf{b}$, $\mathbf{2 d}$, and $\mathbf{2 e}$, together with the X-ray structure of the monostoppered $\mathrm{Cr}_{7} \mathrm{Fe}$-pseudorotaxane (2f) isolated from the reaction mixture that formed rotaxane $\mathbf{2 c}$, are shown in Figure 1. The crystal structures of $\mathbf{2} \mathbf{a}$ and $\mathbf{2} \mathbf{b}$ (Figure $1 \mathbf{a}-\mathbf{c}$ ) are almost isostructural, with the divalent metal ion delocalized over the eight metal sites and the ammonium thread cation at the center of the cavity of the macrocycle forming short (2.00-2.03 $\AA$ ), close-to-linear $\left(167.7^{\circ}-171.6^{\circ}\right) \mathrm{F}^{-} \cdot \cdots \mathrm{HN}^{+}$hydrogen bonds to two of the bridging fluoride ligands. In the $\mathrm{Cr}_{7} \mathrm{Fe}$-pseudorotaxane

(4) (a) Lee, C.-F.; Leigh, D. A.; Pritchard, R. G.; Schultz, D.; Teat, S. J. Timco, G. A.; Winpenny, R. E. P. Nature 2009, 458, 314-318. (b) Brechin, E. K.; Cronin, L. Angew. Chem., Int. Ed. 2009, 48, 69486949.

(5) (a) Anelli, P. L.; Spencer, N.; Stoddart, J. F. J. Am. Chem. Soc. 1991, 113, 5131-5133. (b) Bissell, R. A.; Cordova, E.; Kaifer, A. E.; Stoddart, J. F. Nature 1994, 369, 133-136. (c) Tian, H.; Wang, Q.-C. Chem. Soc. Rev. 2006, 35, 361-374.

(6) Kay, E. R.; Leigh, D. A.; Zerbetto, F. Angew. Chem. Int. Ed. 2007 46, 72-191.

(7) (a) Larsen, F. K.; McInnes, E. J. L.; El Mkami, H.; Overgaard, J.; Piligkos, S.; Rajaraman, G.; Rentschler, E.; Smith, A. A.; Smith, G. M.; Boote, V.; Jennings, M.; Timco, G. A.; Winpenny, R. E. P. Angew. Chem., Int. Ed. 2003, 42, 101-105. (b) Cador, O.; Gatteschi, D.; Sessoli, R.; Larsen, F. K.; Overgaard, J.; Barra, A.-L.; Teat, S. J.; Timco, G. A.; Winpenny, R. E. P. Angew. Chem., Int. Ed. 2004, 43, 5196-5200. (c) Timco, G. A.; Batsanov, A. S.; Larsen, F. K.; Muryn, C. A.; Overgaard, J.; Teat, S. J.; Winpenny, R. E. P. Chem. Commun. 2005, 3649-3651. (d) Affronte, M.; Carretta, S.; Timco, G. A. Winpenny, R. E. P. Chem. Commun. 2007, 1789-1797.

(8) For some related metallic ring systems, see: (a) Gerbeleu, N. V.; Batsanov, A. S.; Timko, G. A.; Struchkov, Yu. T.; Indrichan, K. M.; Popovich, G. A. Patent SU 1299116, 1985. (b) Taft, K. L.; Lippard, S. J. J. Am. Chem. Soc. 1990, 112, 9629-9630. (c) Gerbeleu, N. V.; Struchkov, Yu. T.; Timco, G. A.; Batsanov, A. S.; Indrichan, K. M.; Popovich, G. A. Dokl. Akad. Nauk SSSR 1990, 313, 1459-1462. (d) Stemmler, A. J.; Kampf, J. W.; Pecoraro, V. L. Inorg. Chem. 1995, 34, 2271-2271. (e) Caneschi, A.; Cornia, A.; Fabretti, A. C.; Gatteschi, D. Angew. Chem., Int. Ed. 1999, 39, 1295-1297. (f) Waldmann, O. Koch, R.; Schromm, S.; Schülein, J.; Müller, P.; Bernt, I.; Saalfrank, R. W.; Hampel, F.; Balthes, E. Inorg. Chem. 2001, 40, 2986-2995. (g) Tasiopoulos, A. J.; Vinslava, A.; Wernsdorfer, W.; Christou, G. Angew. Chem. Int. Ed. 2004, 43, 2117-2121. (h) King, P.; Stamatos, T. C.; Abboud, K. A.; Christou, G. Angew. Chem., Int. Ed. 2006, 45, 7379-7383. (i) Low, D. M.; Rajaraman, G.; Helliwell, M.; Timco, G. A.; van Slageren, J.; Sessoli, R.; Ochsenbein, S. T.; Bircher, R.; Dobe, C.; Waldmann, O.; Güdel, H. U.; Adams, M. A.; Ruiz, E.; Alvarez, S.; McInnes, E. J. L. Chem.-Eur. J. 2006, 12, 1385-1396. (j) Mezei, G.; Zaleski, C. M.; Pecoraro, V. L. Chem. Rev. 2007, 107, 4933-5003.

(9) (a) Leuenberger, M. N.; Loss, D. Nature 2001, 410, 789-793. (b) Meier, F.; Levy, J.; Loss, D. Phys. Rev. Lett. 2003, 90, 047901/1047901/4. (c) Bertaina, S.; Gambarelli, S.; Mitra, T.; Tsukerblat, B.; Müller, A.; Barbara, B. Nature 2008, 453, 203-206. (d) Timco, G. A.; Carretta, S.; Troiani, F.; Tuna, F.; Pritchard, R. G.; McInnes, E. J. L.; Ghirri, A.; Candini, A.; Santini, P.; Amoretti, G.; Affronte, M.; Winpenny, R. E. P. Nat. Nanotechnol. 2009, 4, 173-178.

(10) (a) Kolchinski, A. G.; Busch, D. H.; Alcock, N. W. J. Chem. Soc. Chem. Commun. 1995, 1289-1291. (b) Ashton, P. R.; Glink, P. T.; Stoddart, J. F.; Tasker, P. A.; White, A. J. P.; Williams, D. J. Chem.-Eur. J. 1996, 2, 729-736.

(11) (a) Mock, W. L.; Irra, T. A.; Wepsiec, J. P.; Adhia, M. J. Org. Chem. 1989, 54, 5302-5308. (b) Kim, K. Chem. Soc. Rev. 2002, 31, 96 107.

(12) Aucagne, V.; Leigh, D. A.; Lock, J. S.; Thomson, A. R. J. Am. Chem. Soc. 2006, 128, 1784-1785.

(13) The use of threads with eight methylene groups between two amine groups can lead to the formation of [3]-and [4]rotaxanes (see ref 4). 2f (Figure 1f) the heterometallic ring is slightly rotated with respect to the thread compared to the other solid state structures so that four fluoride anions form the closest contacts with the hydrogen atoms of the ammonium groups. These interactions are longer $\left(2.14-2.23 \AA\right.$ ) and rather less linear $\left(131.2^{\circ}-153.0^{\circ}\right)$ than the $\mathrm{F}^{-} \cdot \cdots \mathrm{HN}^{+}$hydrogen bonds in the $\mathrm{Cr}_{7} \mathrm{Co}-, \mathrm{Cr}_{7} \mathrm{Ni}$-, and $\mathrm{Cr}_{7} \mathrm{Mn}$-rotaxanes (Figure 1a-d), illustrating that the interactions of the ammonium group with the various electronegative regions of the heterometallic wheel are a delicate balance of electrostatics (where the close contacts need not be in line with the $\mathrm{H}-\mathrm{N}$ bonds) as well as conventional hydrogen bonding. In the crystal structure of the $\mathrm{Cr}_{7} \mathrm{Mn}$-[2]rotaxane $2 \mathbf{d}$ (Figure 1d) the manganese ion is localized in the position shown (i.e., the divalent metal ion is not delocalized as it is in the other X-ray structures). The two $\mathrm{F}^{-} \cdots \mathrm{HN}^{+}$hydrogen bonds of the $\mathrm{Cr}_{7} \mathrm{Cu}$-[2]rotaxane 2e (Figure 1e) are less similar to each other $\left(1.95 \AA\right.$, $161.0^{\circ} \mathrm{cf}$. $\left.2.18 \AA, 165.5^{\circ}\right)$ than in the other rotaxanes, perhaps reflecting that the $\mathrm{Cr}_{7} \mathrm{Cu}$ system has slightly different steric and/or electronic characteristics compared to the other heterometallic wheels.

Although the eight metal centers in the heterometallic rings are almost perfectly coplanar in each crystal structure, making the two faces virtually identical in terms of physical shape and geometry, the macrocycles are all chiral. The enantiomers differ in that the one divalent metal ion (Co(II), Ni(II), Fe(II), Mn(II) or $\mathrm{Cu}(\mathrm{II})$ ) in each ring must have either a $(\Delta)$ - or $(\Lambda)$ arrangement of the ligands in its octahedral coordination sphere. Only one enantiomer is shown in Figure 1 for each rotaxane, but both enantiomers are present in equal amounts in each crystal.

X-ray crystallography of single crystals grown by a variety of methods (see Supporting Information) was routinely used, together with electrospray ionization mass spectrometry (ESI$\mathrm{MS}$ ), to determine the structures of the products of the rotaxaneforming reactions. Nuclear magnetic resonance (NMR) spectroscopy proved useful only for the rotaxanes incorporating $\mathrm{Co}(\mathrm{II})$ and $\mathrm{Fe}$ (II) as the divalent metals (2a and 2c, respectively). ${ }^{14}$ The ${ }^{1} \mathrm{H}$ NMR spectrum of $\mathbf{2 a}$ (Figure $2 \mathrm{~b}$ ) shows the unequal magnetic effect exerted on each geminal proton in the methylene groups of the thread due to the chirality of the ring. Two signals are observed for each pair of methylene protons, due to the two protons of each methylene group (labeled primed and unprimed in Figure 2) being diastereotopic (i.e., magnetically distinct) as a result of the chirality of the heterometallic ring. ${ }^{15}$ Comparison of the ${ }^{1} \mathrm{H}$ NMR spectrum of the parent thread, 1 (Figure 2a), with that of the rotaxane, 2a (Figure 2b), and a partially deuterated analogue, $d_{144}$-2a (Figure $2 \mathrm{c}$ ), shows the dramatic shifts in the thread protons caused by the paramagnetic $\mathrm{Cr}$ (III) and $\mathrm{Co}$ (II) ions, the greatest shifts generally occurring for the protons closest to the heterometallic ring.

The presence of one $\mathrm{Co}$ (II) ion among seven $\mathrm{Cr}$ (III) ions desymmetrizes the ring, resulting in the 16 pivalate groups being in eight magnetically nonequivalent environments (four axial and four equatorial). Slow rotation of the ring about the thread on the NMR time scale (up to eight different $\mathrm{C}_{8}$-rotational positions of the divalent metal ion around the thread for each of the eight different types of pivalate groups) would result in

(14) The possibility of using ${ }^{1} \mathrm{H}$ NMR analysis is the reason the $\mathrm{Cr}_{7} \mathrm{Co}$ rotaxane forming reaction was studied in the most detail. For the ${ }^{1} \mathrm{H}$ NMR spectrum of the amide-stoppered $\mathrm{Cr}_{7} \mathrm{Co}$-[2]rotaxane $4 \mathbf{a}$ and $\mathrm{Cr}_{7} \mathrm{Fe}-[2]$ rotaxane $\mathbf{4 c}$, see the Supporting Information.

(15) Sanudo, E. C.; Faust, T. B.; Muryn, C. A.; Pritchard, R. G.; Timco, G. A.; Winpenny, R. E. P. Inorg. Chem. 2009, 48, 9811-9818. 


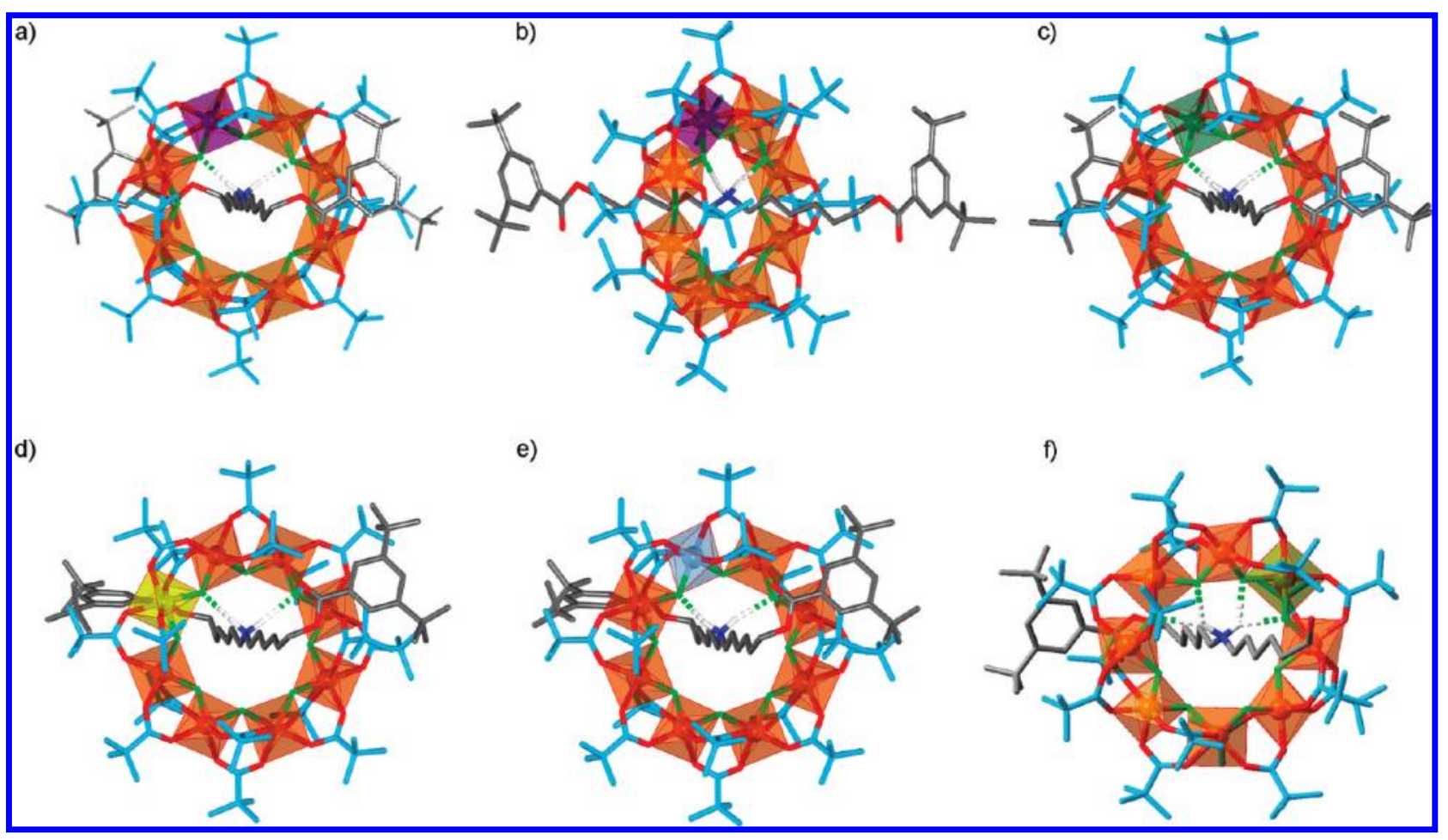

Figure 1. X-ray crystal structures of hybrid organic-inorganic [2]rotaxanes with 3,5-di-tert-butylbenzoate stoppers, 2a, 2b, 2d, and 2e, and $\mathrm{Cr}_{7} \mathrm{Fe}$-pseudorotaxane 2f. (a) Facial view of $\mathrm{Cr}_{7} \mathrm{Co}$-[2]rotaxane $\mathbf{2 a}{ }^{4 a}$ (b) Side view of $\mathrm{Cr}_{7} \mathrm{Co}$-[2]rotaxane $\mathbf{2 a}{ }^{4 a}$ (c) $\mathrm{Cr}_{7} \mathrm{Ni}$-[2]rotaxane $\mathbf{2 b}$. (d) $\mathrm{Cr}_{7} \mathrm{Mn}$-[2]rotaxane 2d. (e) $\mathrm{Cr}_{7} \mathrm{Cu}$-[2] rotaxane 2e. (f) $\mathrm{Cr}_{7} \mathrm{Fe}$-pseudo[2] rotaxane $\mathbf{2 f}$ (note only one stopper group is present on the thread). For clarity carbon atoms of the thread are shown in gray, carbon atoms of the pivalate groups in light blue, oxygen atoms in red, nitrogen in dark blue, fluorine in green, cobalt in purple, nickel in dark green, iron in dark yellow, manganese in yellow, copper in pale blue, and chromium in orange. Hydrogen atoms (white) other than those of the ammonium group are omitted for clarity. In (a), (b), (c), (e), and (f), the divalent metal ion (Co(II), $\mathrm{Ni}$ (II), $\mathrm{Cu}$ (II), $\mathrm{Fe}$ (II)) is disordered over the eight metal sites in each heterometallic ring and the structures are shown with the divalent metal ion having a $(\Lambda)$-arrangement of the ligands. In (d) the divalent metal ion $(\mathrm{Mn}(\mathrm{II}))$ is localized at the position indicated and is shown with a $(\Delta)$-arrangement of the ligands. Hydrogen-bond (shown as dashed cylinders) lengths and $\mathrm{N}-\mathrm{H}-\mathrm{F}$ angles are $(\mathrm{a}$ and $\mathrm{b}) \mathrm{NH} 1 \cdots \mathrm{F} 1=2.03 \AA . \mathrm{NH} 2 \cdots \mathrm{F} 7=2.01 \AA, \mathrm{N}-\mathrm{H} 1-\mathrm{F} 1=168.9^{\circ}, \mathrm{N}-\mathrm{H} 2-\mathrm{F} 7=168.2^{\circ} ;(\mathrm{c}) \mathrm{NH} 1 \cdots \mathrm{F} 4=2.00 \AA$, $\mathrm{NH} 2 \cdots \mathrm{F} 2=2.02 \AA, \mathrm{N}-\mathrm{H} 1-\mathrm{F} 4=167.9^{\circ}, \mathrm{N}-\mathrm{H} 2-\mathrm{F} 2=167.7^{\circ} ;$ (d) $\mathrm{NH} 1 \cdots \mathrm{F} 4=2.13 \AA, \mathrm{NH} 2 \cdots \mathrm{F} 6=2.11 \AA ⿻ \mathrm{~N}-\mathrm{H} 1-\mathrm{F} 4=169.7^{\circ}, \mathrm{N}-\mathrm{H} 2-\mathrm{F} 6=$ $171.6^{\circ}$; (e) $\mathrm{NH} 1 \cdots \mathrm{F} 7=1.95 \AA, \mathrm{NH} 2 \cdots \mathrm{F} 1=2.18 \AA, \mathrm{N}-\mathrm{H} 1-\mathrm{F} 7=161.0^{\circ}, \mathrm{N}-\mathrm{H} 2-\mathrm{F} 1=165.5^{\circ}$; (f) $\mathrm{NH} 1 \cdots \mathrm{F} 7=2.20 \AA, \mathrm{NH} 1 \cdots \mathrm{F} 8=2.14 \AA, \mathrm{NH} 2 \cdots \mathrm{F} 1$ $=2.23 \AA, \mathrm{NH} 2 \cdots \mathrm{F} 2=2.19 \AA, \mathrm{N}-\mathrm{H} 1-\mathrm{F} 1=153.0^{\circ}, \mathrm{N}-\mathrm{H} 1-\mathrm{F} 8=131.2^{\circ}, \mathrm{N}-\mathrm{H} 2-\mathrm{F} 1=135.8^{\circ}, \mathrm{N}-\mathrm{H} 2-\mathrm{F} 2=148.9^{\circ}$. Crystallographic data and experimental details of the structural refinement for $\mathbf{2} \mathbf{a}-\mathbf{f}$ are provided in the Supporting Information.

many different sets of signals for the pivalate groups. However only eight resonances for pivalate groups (blue signals in Figure 2b) are observed in the spectrum of $\mathbf{2} \mathbf{a}$, consistent with rapid rotation of the ring on the NMR time scale.

Optimization of Rotaxane Yield. During the course of these studies we found, by accidentally introducing an impurity into a rotaxane-forming reaction, ${ }^{4}$ that the presence of ammonium salts could significantly alter the yield in the hybrid organicinorganic rotaxane-forming reactions. To study the effect of such additives on rotaxane formation, the synthesis of $\mathrm{Cr}_{7} \mathrm{Co}$-rotaxane 2a was carried out in the presence of differing quantities of (a) diethylamine, (b) triethylamine, (c) (chloromethyl)triethylammonium chloride, and (d) tetraethylammonium chloride (Scheme 2). The results are shown in Figure 3.

Diethylamine is a good template for the formation of the octametallic ring, forming $\left[\mathrm{H}_{2} \mathrm{NEt}_{2}\right]\left[\mathrm{Cr}_{7} \mathrm{CoF}_{8}\left(\mathrm{O}_{2} \mathrm{C}^{t} \mathrm{Bu}\right)_{16}\right], \mathbf{5}$, in $68 \%$ yield from the cocktail of metal salts and pivalic acid used in the assembly process. ${ }^{7 a}$ Thus when diethylamine was added to the rotaxane-forming reaction, $\mathbf{5}$ was isolated from the reaction (several other, unidentified, side products were also formed) as well as rotaxane $\mathbf{2} \mathbf{a}$, with the ratio of $\mathbf{2} \mathbf{a} / \mathbf{5}$ reflecting the competition between the two amines (thread $\mathbf{1}$ and diethylamine) for the ring (Figure 3, trace (a)). When more than 20 mol \% of diethylamine was used the yield of rotaxane $\mathbf{2 a}$ decreased from the $23 \%$ yield obtained with no additive (Scheme 1). Interestingly, however, when less than $20 \mathrm{~mol} \%$ of dieth- ylamine was used, the yield of rotaxane $2 \mathrm{a}$ increased up to $58 \%$ (Figure 3, trace (a)). When (chloromethyl)triethylammonium chloride was added to the reaction mixture instead (Figure 3, trace (c)), $\mathbf{5}$ was also isolated as a side product, the diethylammonium cation apparently being generated under the reaction conditions. The yield of rotaxane $\mathbf{2 a}$ was increased by the use of this salt at any ratio, with the best result (58\% rotaxane $\mathbf{2 a}$ ) obtained with a loading of $30 \mathrm{~mol} \%$. Even higher yields of rotaxane were observed using triethylamine as an additive, with $65-70 \%$ of 2 a obtained with $5-100$ mol \% triethylamine (Figure 3, trace (b)), without the accompanying formation of $\mathbf{5}$ although other byproducts were formed. Finally, tetraethylammonium chloride improved the yield of $\mathbf{2} \mathbf{a}$ when present in more than $20 \mathrm{~mol} \%$ (Figure 3, trace (d)). In contrast to the other three additives, the use of $\mathrm{Et}_{4} \mathrm{NCl}$ in the rotaxane-forming reaction did not produce $\mathbf{5}$ or any other side products. This makes purification of the rotaxane easier, and it may be the additive of choice for most rotaxane-forming protocols.

The role of these additives is presumably to template the assembly of the heterometallic ring, or large oligomers ${ }^{16}$ that can readily form the ring, and the additives may play this role better than the thread does itself. The additives will form dynamic complexes with such species whereas the thread cannot decomplex from the wheel once the rotaxane has been formed without several metal-ligand bonds being broken concurrently. When not complexed with an ammonium group, the ring will 


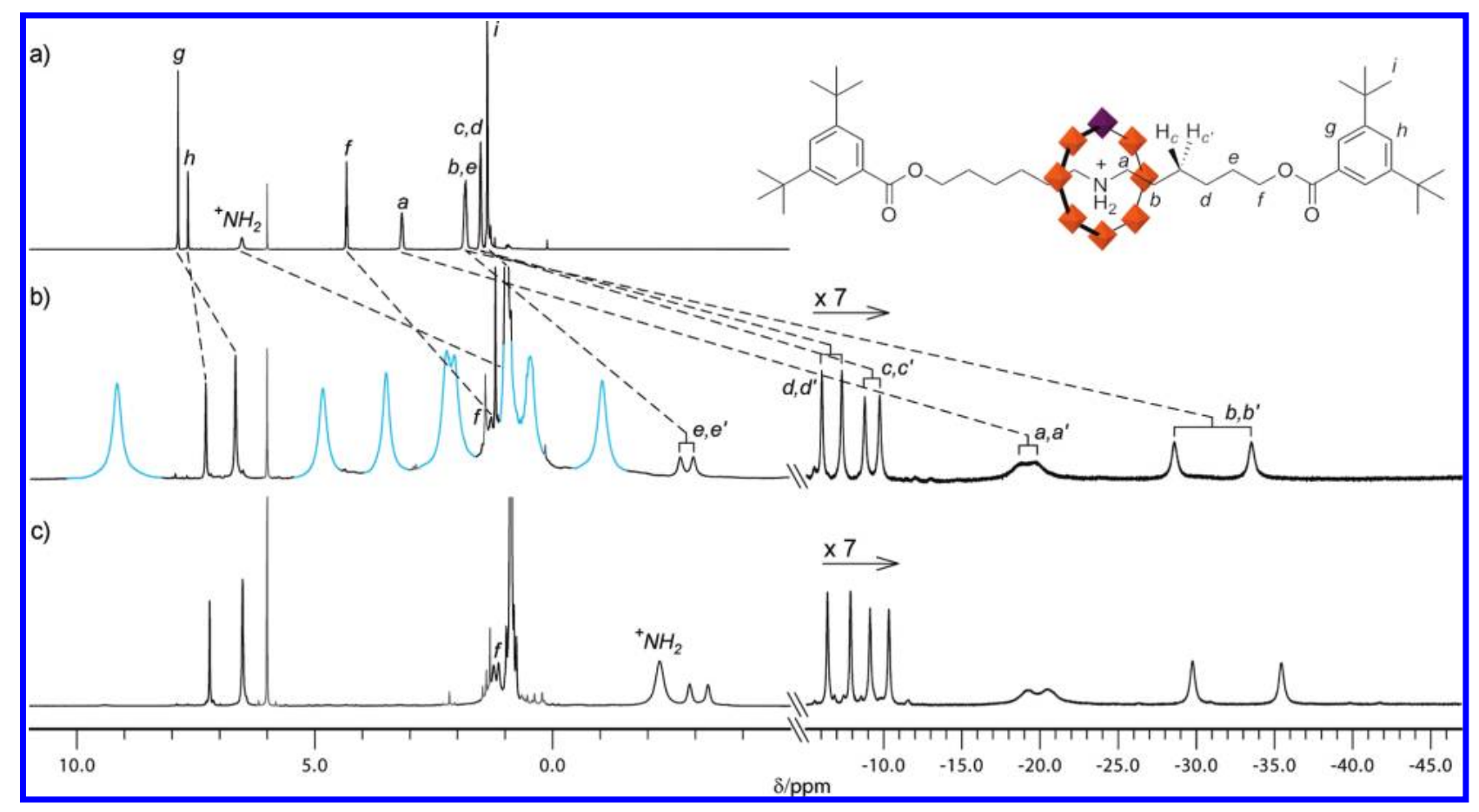

Figure 2. ${ }^{1} \mathrm{H}$ NMR spectra $\left(500 \mathrm{MHz}, \mathrm{C}_{2} \mathrm{D}_{2} \mathrm{Cl}_{4}, 330 \mathrm{~K}\right.$ ). (a) Thread $\mathbf{1} \cdot \mathrm{PF}_{6}{ }^{-}$. (b) [2]rotaxane 2a. (c) $d_{144}-\mathbf{2 a}$. The eight signals shown in blue in spectrum (b) are due to the 48 pivalate methyl groups of the macrocycle. Per-deuterating the pivalate methyl groups facilitates characterization of the relatively low intensity thread protons in the rotaxane (spectrum (c)). The rotaxane signals below $-5 \mathrm{ppm}$ are shown at $7 \times$ magnification and on a compacted $X$-axis compared to the signals above $-5 \mathrm{ppm}$. Residual solvent peaks and impurities are shown in gray.

Scheme 2. Synthesis of $\mathrm{Cr}_{7} \mathrm{Co}-[2]$ Rotaxane $\mathbf{2 a}$ in the Presence of Additives $^{a, b}$

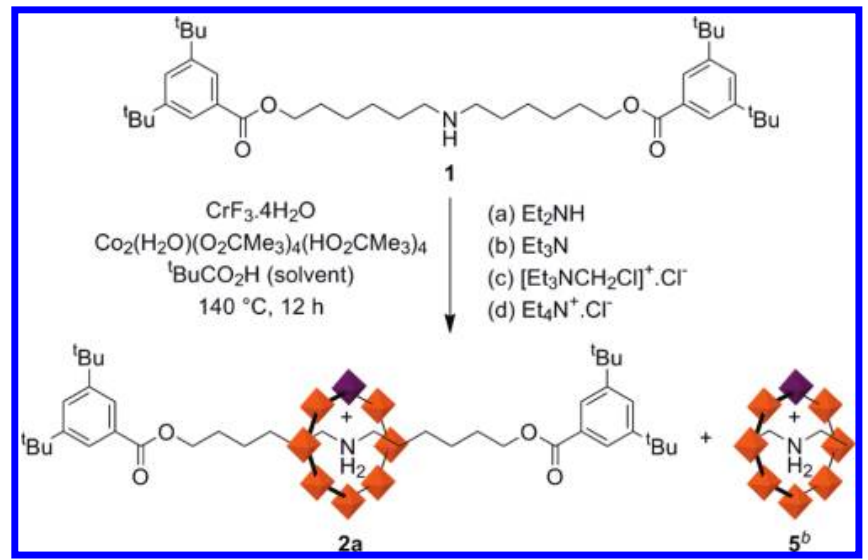

${ }^{a}$ Reaction conditions for the synthesis of [2]rotaxane $\mathbf{2 a}$ in presence of various amounts of additive (a) diethylamine, (b) triethylamine, (c) (chloromethyl)triethylammonium chloride, or (d) tetraethylammonium chloride: 1 ( 1 equiv), additive $\left(0.05-1\right.$ equiv), $\mathrm{CrF}_{3} \cdot 4 \mathrm{H}_{2} \mathrm{O}$ (5 equiv), $\left[\mathrm{Co}\left(\mathrm{OH}_{2}\right)\left(\mathrm{O}_{2} \mathrm{CCMe}_{3}\right)_{4}\left(\mathrm{HO}_{2} \mathrm{CCMe}_{3}\right)_{4}\right]$ (1 equiv), pivalic acid (50-60 equiv), $140{ }^{\circ} \mathrm{C}, 12 \mathrm{~h}$. Isolated yields (Figure 3 ) are based on $\mathrm{Cr}(\mathrm{III})$ as the limiting reagent. ${ }^{b}$ Pseudorotaxane $\mathbf{5}$ was formed as a side product only when diethylamine (a) or (chloromethyl)triethylammonium chloride (c) was used as the additive.

be relatively unstable and more subject to ligand exchange. In other words, the additives probably act as templates that assemble large fragments of the heterometallic wheel that are then kinetically trapped as the rotaxane by the stoppered thread.

Kinetic Stability of $\mathrm{Cr}_{7} \mathbf{C o}$-[2]Rotaxane 2a. Although the metal-ligand bonds must be reversibly formed to some degree under the conditions that the rotaxanes are assembled (pivalic acid as solvent, $140{ }^{\circ} \mathrm{C}, 12 \mathrm{~h}$ ), the hybrid organic-inorganic rotaxanes proved to be kinetically stable under less harsh conditions (Scheme 3). Rotaxane 2a showed no evidence of

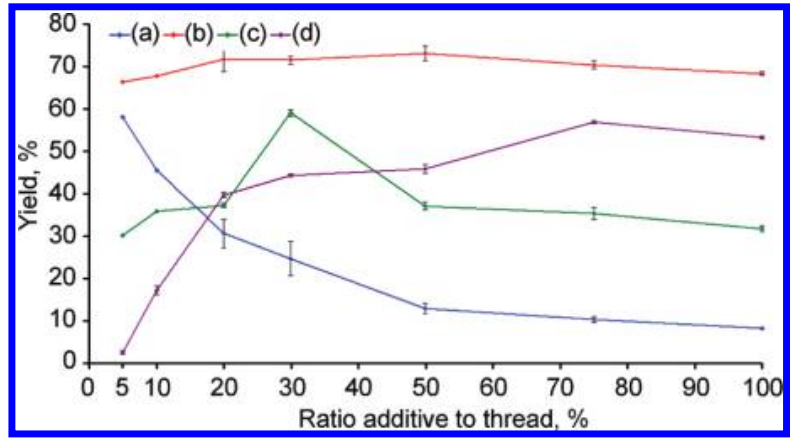

Figure 3. Yield of $\mathrm{Cr}_{7} \mathrm{Co}$-rotaxane 2a (Scheme 2) as a function of the presence of various amounts of different additives: (a) diethylamine, (b) triethylamine, (c) (chloromethyl)triethylammonium chloride, (d) tetraethylammonium chloride. Each data point is the average of at least two experiments. Vertical error bars show the yields obtained from different runs.

dethreading or decomposition after 1 week at $60{ }^{\circ} \mathrm{C}$ in $\mathrm{C}_{2} \mathrm{D}_{2} \mathrm{Cl}_{4}$. An isotopically labeled analogue in which the pivalate groups were perdeuterated, $d_{144}-\mathbf{2} \mathbf{a}$, was added, and the mixture was left for a further week at $60{ }^{\circ} \mathrm{C}$ (Scheme 3a). No exchange of pivalate ligands (which would indicate disassembly/reassembly of the heterometallic ring was occurring) was observed by mass spectrometry. At $140{ }^{\circ} \mathrm{C}$, the mixture of [2]rotaxane $2 \mathbf{a}$ and its deuterated analogue $d_{144}-\mathbf{2 a}$ in $\mathrm{C}_{2} \mathrm{D}_{2} \mathrm{Cl}_{4}$ did undergo scrambling of the pivalate ligands and about $90 \%$ of the rings had exchanged at least 1 of their 16 pivalate groups after $48 \mathrm{~h}$. In order to be certain that the ring does not slip off the thread and reassemble

(16) The most likely candidates for oligomeric precursors to the macrocycles are $\mathrm{Cr}_{6}$-'horseshoes', which form readily in similar reactions in the presence of dialkylamines when the divalent metal is absent. See: Larsen, F. K.; Overgaard, J.; Parsons, S.; Rentschler, E.; Timco, G. A.; Smith, A. A.; Winpenny, R. E. P. Angew. Chem. Int. Ed. 2003, 42, 5978-5981. 
Scheme 3. Pivalate-Exchange Reactions between (a) [2]Rotaxanes 2a and $d_{144}-2 \mathbf{a}$ and (b) [2]Rotaxanes $d_{144}-2 \mathrm{a}$ and $4 \mathbf{a}$

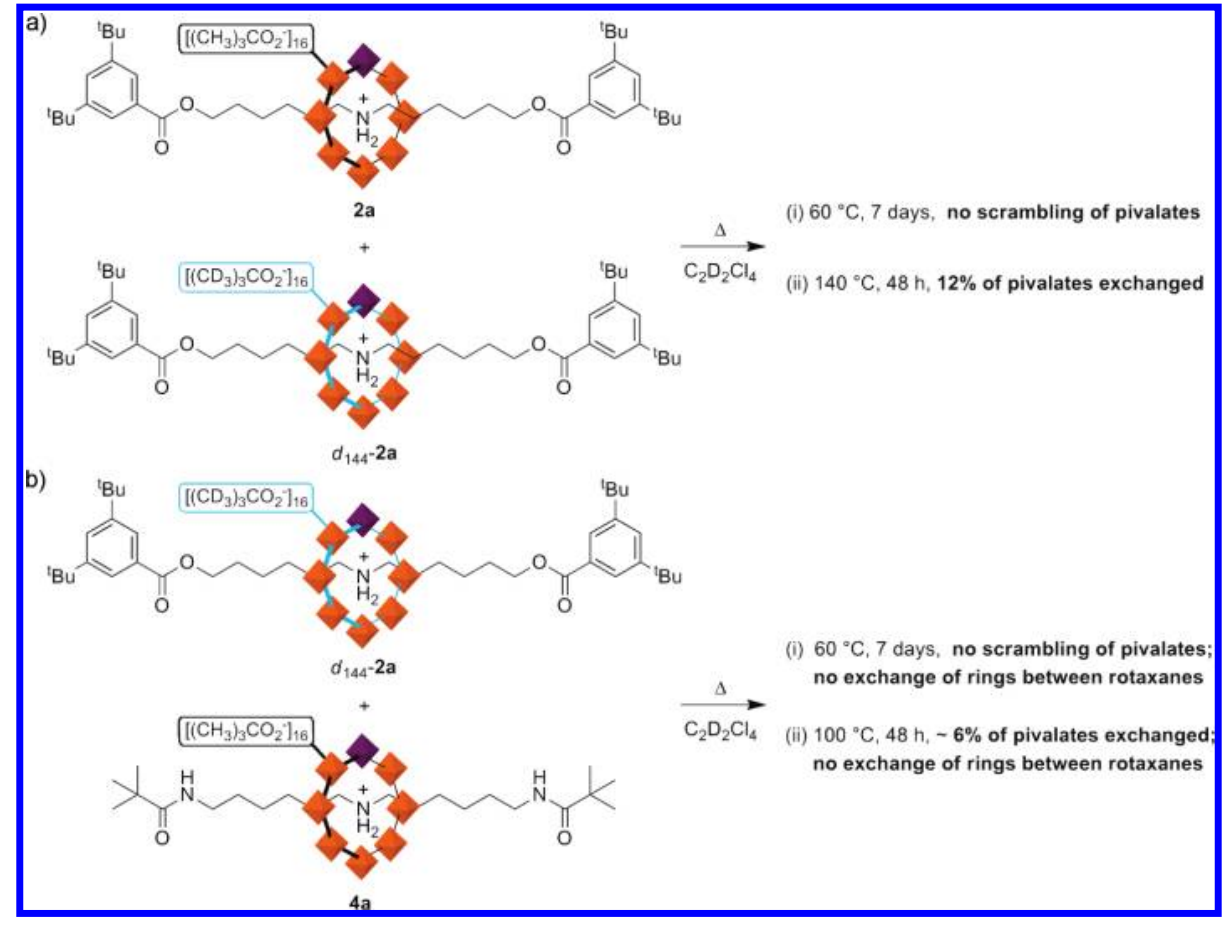

around another one, a second experiment was conducted (Scheme 3b). A mixture of [2] rotaxane with different rings (one isotopically labeled, one not) and stoppers, $d_{144}-\mathbf{2 a}$ and $\mathbf{4 a}$ (for the synthesis of rotaxane $\mathbf{4 a}$, see Scheme 4), was stirred for 1 week in $\mathrm{C}_{2} \mathrm{D}_{2} \mathrm{Cl}_{4}$ at $60{ }^{\circ} \mathrm{C}$. No exchange of the heterometallic rings between the threads was observed by ESI-MS. At $100{ }^{\circ} \mathrm{C}$ the scrambling of individual pivalate groups did occur over $48 \mathrm{~h}$, but still under these conditions there was no whole ring transfer between the two [2]rotaxanes.

Changing the End Groups of the Thread: One Pot 'StopperingPlus-Macrocyclization' Assembly of [2]Rotaxanes 4a-g. Although the benzoate esters used to stopper the threads in rotaxanes $\mathbf{2} \mathbf{a}-\mathbf{e}$ are reasonably stable to the rather harsh conditions used in the rotaxane-forming reaction (pivalic acid at $140{ }^{\circ} \mathrm{C}$ ), some cleavage of the ester groups was observed in reaction byproducts (e.g., pseudorotaxanes of the mono-ol or diol derived from the thread; for example, 2f, Scheme 1 and Figure 1f). The use of simple (nonstoppered) dialkylamines (such as $\mathrm{Et}_{2} \mathrm{NH}, n \mathrm{Pr}_{2} \mathrm{NH}$, $\left.n \mathrm{Bu}_{2} \mathrm{NH}\right)$ as templates ${ }^{7}$ generates the heterometallic wheels in good yields (up to $68 \%{ }^{7 \mathrm{a}}$ ), suggesting that the bulkiness of the stoppers might make the secondary amine in $\mathbf{1}$ a relatively poor template. Accordingly we investigated the possibility of using a smaller, more stable, stoppering group for the assembly of rotaxanes. CPK models suggested that the heterometallic ring cavities are small enough that even a tert-butylamide group should prevent dethreading, and so bis(hexamethylene)triamine 3 was used to assemble another series of [2] rotaxanes in a stoppering-plus-macrocyclization reaction that utilizes both pivalic acid and pivalic anhydride ${ }^{17}$ (Scheme 4). Under these reaction conditions, in addition to the template macrocyclization of the heterometallic wheel about the thread, the primary amines at either end of $\mathbf{3}$ react to form amides leading to the one-pot

(17) The amide-stoppered rotaxanes also form under the original reaction conditions (Scheme 1). However, the addition of pivalic anhydride increases the yield and decreases the reaction time required for efficient rotaxane formation.
Scheme 4. One-Pot 'Stoppering-Plus-Macrocyclization' Reaction To Assemble tBuCONH-Stoppered [2]Rotaxanes $\mathbf{4 a}-\mathbf{g}^{\mathrm{a}}$

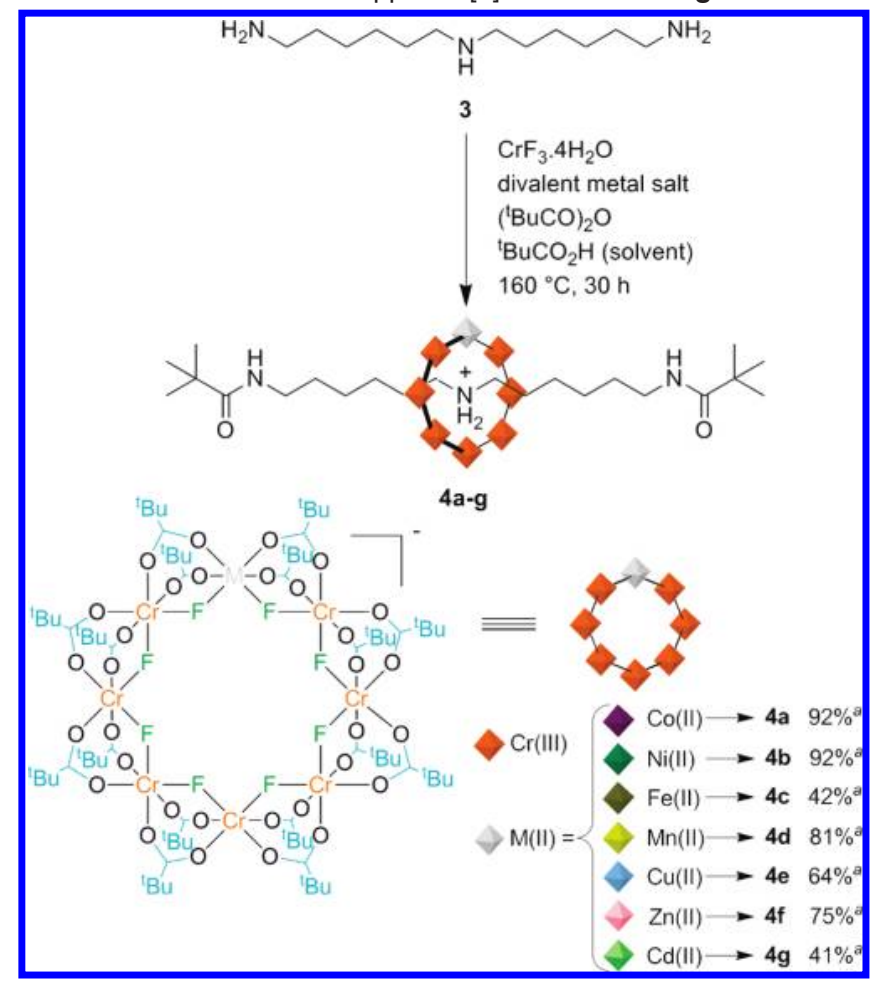

${ }^{a}$ Reaction conditions for the synthesis of [2] rotaxanes with ${ }^{t} \mathrm{BuCONH}$ stoppers, $4 \mathbf{a}-\mathbf{g}: 3$ ( 1 equiv), $\mathrm{CrF}_{3} \cdot 4 \mathrm{H}_{2} \mathrm{O}$ (5 equiv), divalent metal salt $\left(\left[\mathrm{Co}\left(\mathrm{O}_{2} \mathrm{CCMe}_{3}\right)_{2}\right],\left[\mathrm{Ni}\left(\mathrm{OH}_{2}\right)\left(\mathrm{O}_{2} \mathrm{CCMe}_{3}\right)_{4}\left(\mathrm{HO}_{2} \mathrm{CCMe}_{3}\right)_{4}\right], \mathrm{Fe}\left(\mathrm{O}_{2} \mathrm{CCH}\right)_{2} \cdot 2 \mathrm{H}_{2} \mathrm{O}\right.$, $\left.\mathrm{MnCO}_{3} \cdot 2 \mathrm{H}_{2} \mathrm{O}, \mathrm{CuCO}_{3} \cdot \mathrm{Cu}(\mathrm{OH})_{2},\left[\mathrm{ZnCO}_{3}\right]_{2} \cdot\left[\mathrm{Zn}(\mathrm{OH})_{2}\right]_{3}, \mathrm{CdCO}_{3}\right)$ (1 equiv), pivalic anhydride (6 equiv), pivalic acid (50-60 equiv), $160{ }^{\circ} \mathrm{C}, 30 \mathrm{~h}$. Isolated yields are based on $\mathrm{Cr}(\mathrm{III})$ as the limiting reagent.

formation of amide-stoppered rotaxanes $\mathbf{4 a}-\mathbf{e}$ when $\mathrm{Co}(\mathrm{II})$, $\mathrm{Ni}(\mathrm{II}), \mathrm{Fe}(\mathrm{II}), \mathrm{Mn}(\mathrm{II})$, or $\mathrm{Cu}(\mathrm{II})$ was used as the divalent metal. The [2]rotaxanes $(\mathbf{4 a}-\mathbf{e})$ assembled by this simultaneous stoppering and macrocyclization protocol were obtained in 


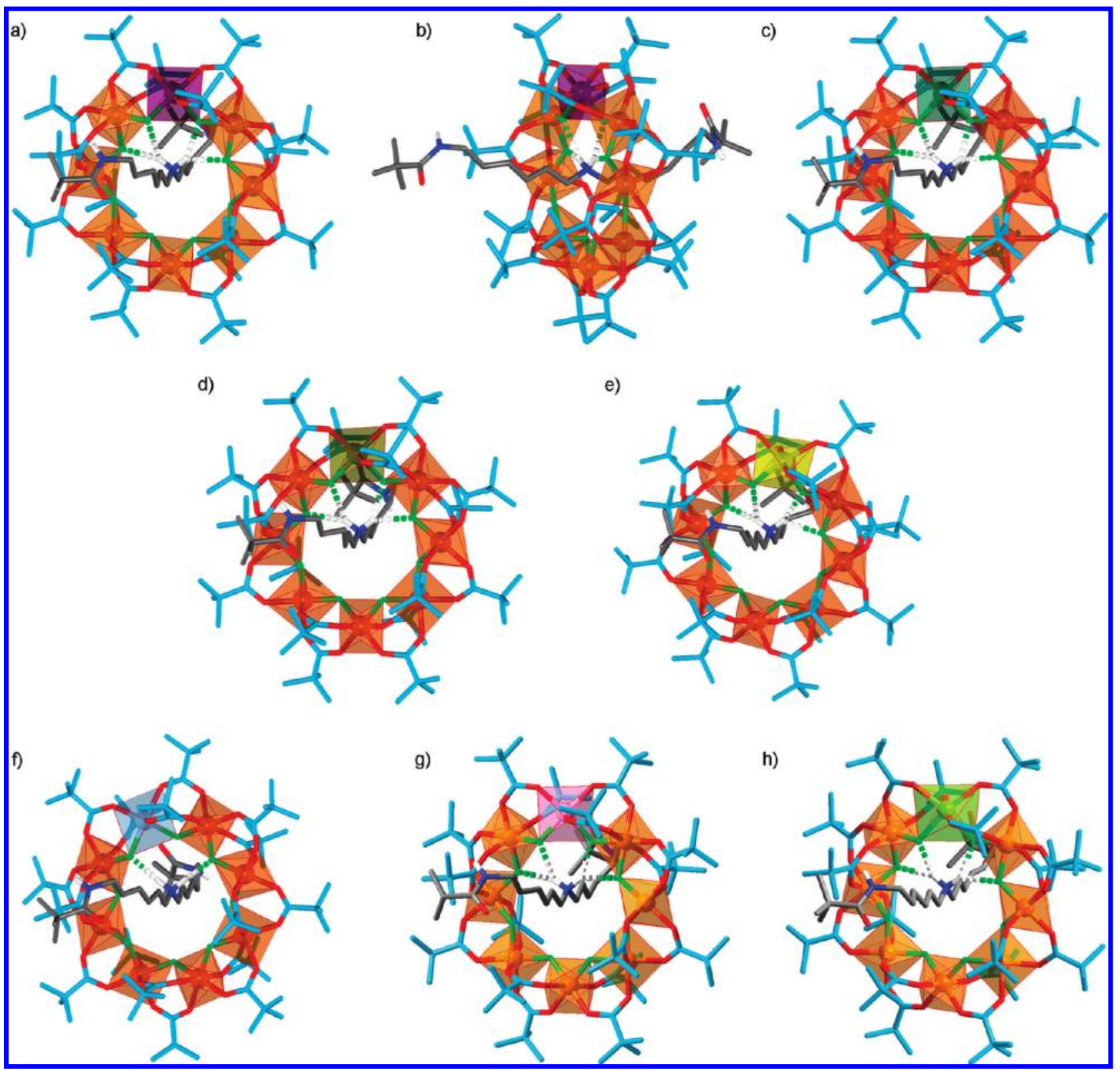

Figure 4. X-ray crystal structures of hybrid organic-inorganic [2]rotaxanes with ${ }^{t} \mathrm{BuCONH}$ stoppers, $\mathbf{4 a}-\mathbf{g}$. (a) $\mathrm{Facial}_{\mathrm{V}} \mathrm{view}_{\mathrm{ef}} \mathrm{Cr} \mathrm{Co}_{7}-[2] \mathrm{rotaxane} \mathbf{4 a}$. (b) Side view of $\mathrm{Cr}_{7} \mathrm{Co}$-[2]rotaxane 4a. (c) $\mathrm{Cr}_{7} \mathrm{Ni}$-[2]rotaxane 4b. (d) $\mathrm{Cr}_{7} \mathrm{Fe}$-[2]rotaxane 4c. (e) $\mathrm{Cr}_{7} \mathrm{Mn}$-[2]rotaxane 4d. (f) $\mathrm{Cr}_{7} \mathrm{Cu}-[2] \mathrm{rotaxane}$ 4e. (g) $\mathrm{Cr} \mathrm{Zn}_{7}$ [2]rotaxane 4f. (h) $\mathrm{Cr}_{7} \mathrm{Cd}$-[2]rotaxane $\mathbf{4 g}$. The atom coloring is as indicated in the Figure 1 caption, plus zinc is pink and cadmium is light green. In (a), (b), (c), (d), (f), and (h), the divalent metal ion ( $\mathrm{Co}(\mathrm{II}), \mathrm{Ni}(\mathrm{II}), \mathrm{Fe}(\mathrm{II}), \mathrm{Cu}(\mathrm{II}), \mathrm{Cd}(\mathrm{II})$ ) is localized at the position indicated in the heterometallic ring and has a $(\Lambda)$ arrangement of the ligands. In (e) and (g) the divalent metal ion ( $\mathrm{Mn}(\mathrm{II})$ and $\mathrm{Zn}(\mathrm{II})$ ) is disordered over the eight metal sites in the heterometallic ring and the structure is shown with the divalent metal ion having a $(\Lambda)$-arrangement of the ligands. Hydrogen-bond (shown as dashed cylinders) lengths and $\mathrm{N}-\mathrm{H}-\mathrm{F}$ angles are (a and b) $\mathrm{NH} 1 \cdots \mathrm{F} 1=2.08 \AA, \mathrm{NH} 1 \cdots \mathrm{F} 2=2.45 \AA$, NH2 $\cdots \mathrm{F} 7=2.23 \AA, \mathrm{NH} 2 \cdots \mathrm{F} 8=2.22 \AA, \mathrm{N}-\mathrm{H} 1-\mathrm{F} 1=145.6^{\circ}, \mathrm{N}-\mathrm{H} 1-\mathrm{F} 2=141.0^{\circ}$, $\mathrm{N}-\mathrm{H} 2-\mathrm{F} 7=150.0^{\circ}, \mathrm{N}-\mathrm{H} 2-\mathrm{F} 8=135.3^{\circ} ;$ (c) $\mathrm{NH} 1 \cdots \mathrm{F} 7=2.32 \AA, \mathrm{NH} 1 \cdots \mathrm{F} 8=2.10 \AA, \mathrm{NH} 2 \cdots \mathrm{F} 1=2.10 \AA, \mathrm{NH} 2 \cdots \mathrm{F} 2=2.32 \AA, \mathrm{N}-\mathrm{H} 1-\mathrm{F} 7=$ $141.9^{\circ}, \mathrm{N}-\mathrm{H} 1-\mathrm{F} 8=142.3^{\circ}, \mathrm{N}-\mathrm{H} 2-\mathrm{F} 1=135.7^{\circ}, \mathrm{N}-\mathrm{H} 2-\mathrm{F} 2=148.6^{\circ} ;(\mathrm{d}) \mathrm{NH} 1 \cdots \mathrm{F} 7=2.28 \AA, \mathrm{NH} 1 \cdots \mathrm{F} 8=2.16 \AA, \mathrm{NH} 2 \cdots \mathrm{F} 1=2.12 \AA, \mathrm{NH} 2 \cdots \mathrm{F} 2$ $=2.40 \AA, \mathrm{N}-\mathrm{H} 1-\mathrm{F} 7=145.5^{\circ}, \mathrm{N}-\mathrm{H} 1-\mathrm{F} 8=139.6^{\circ}, \mathrm{N}-\mathrm{H} 2-\mathrm{F} 1=141.1^{\circ}, \mathrm{N}-\mathrm{H} 2-\mathrm{F} 2=144.9^{\circ} ;$ (e) $\mathrm{NH} 1 \cdots \mathrm{F} 7=2.07 \AA 0 \mathrm{NH} 1 \cdots \mathrm{F} 8=2.21 \AA, \mathrm{NH} 2 \cdots$ $\mathrm{F} 1=1.93 \AA, \mathrm{NH} 2 \cdots \mathrm{F} 2=2.59 \AA, \mathrm{N}-\mathrm{H} 1-\mathrm{F} 7=156.0^{\circ}, \mathrm{N}-\mathrm{H} 1-\mathrm{F} 8=124.8^{\circ}, \mathrm{N}-\mathrm{H} 2-\mathrm{F} 1=160.4^{\circ}, \mathrm{N}-\mathrm{H} 2-\mathrm{F} 2=128.5^{\circ} ;(\mathrm{f}) \mathrm{NH} 1 \cdots \mathrm{F} 2=2.13 \AA$, $\mathrm{NH} 2 \cdots \mathrm{F} 8=2.01 \AA, \mathrm{N}-\mathrm{H} 1-\mathrm{F} 2=167.2^{\circ}, \mathrm{N}-\mathrm{H} 2-\mathrm{F} 8=161.5^{\circ} ;(\mathrm{g}) \mathrm{NH} 1 \cdots \mathrm{F} 1=2.02 \AA, \mathrm{NH} 1 \cdots \mathrm{F} 2=2.43 \AA, \mathrm{NH} 2 \cdots \mathrm{F} 7=2.19 \AA, \mathrm{NH} 2 \cdots \mathrm{F} 8=2.20$ $\AA, \mathrm{N}-\mathrm{H} 1-\mathrm{F} 1=146.6^{\circ}, \mathrm{N}-\mathrm{H} 1-\mathrm{F} 2=139.3^{\circ}, \mathrm{N}-\mathrm{H} 2-\mathrm{F} 7=150.6^{\circ}, \mathrm{N}-\mathrm{H} 2-\mathrm{F} 8=133.4^{\circ}$; (h) $\mathrm{NH} 1 \cdots \mathrm{F} 1=2.05 \AA, \mathrm{NH} 1 \cdots \mathrm{F} 2=2.39 \AA, \mathrm{NH} 2 \cdots \mathrm{F} 7=$ $2.35 \AA, \mathrm{NH} 2 \cdots \mathrm{F} 8=2.08 \AA, \mathrm{N}-\mathrm{H} 1-\mathrm{F} 1=144.0^{\circ}, \mathrm{N}-\mathrm{H} 1-\mathrm{F} 2=142.1^{\circ}, \mathrm{N}-\mathrm{H} 2-\mathrm{F} 7=143.4^{\circ}, \mathrm{N}-\mathrm{H} 2-\mathrm{F} 8=141.9^{\circ}$. Crystallographic data and experimental details of the structural refinement for $\mathbf{4 a}-\mathbf{g}$ are provided in the Supporting Information.

significantly higher yields (up to $92 \%$ ) than the corresponding benzoate ester rotaxanes $(\mathbf{2 a}-\mathbf{e})$. This led us to attempt the rotaxane-forming reaction with $\mathrm{Zn}$ (II) and $\mathrm{Cd}(\mathrm{II})$ salts, which are generally ${ }^{7 \mathrm{~d}}$ poorer divalent metals for the assembly of heterometallic rings but here produced [2] rotaxanes $\mathbf{4 f}$ and $\mathbf{4 g}$ in $75 \%$ and $41 \%$ yields, respectively (Scheme 4). It is unclear as to whether the 'stoppering-plus-macrocyclization' reaction is so effective only because of the greater stability of the end group in the final rotaxane or whether the amines are playing an additional role in the template assembly of the heterometallic ring prior to the acylation of the primary amines. ${ }^{17}$

The X-ray structures of rotaxanes $\mathbf{4 a}-\mathbf{g}$ are shown in Figure 4. There are no intramolecular hydrogen bonding interactions between the tert-butylamide groups of either stopper and the heterometallic ring, probably as a result of the bulkiness of the tert-butyl group adjacent to the amide. The intercomponent 


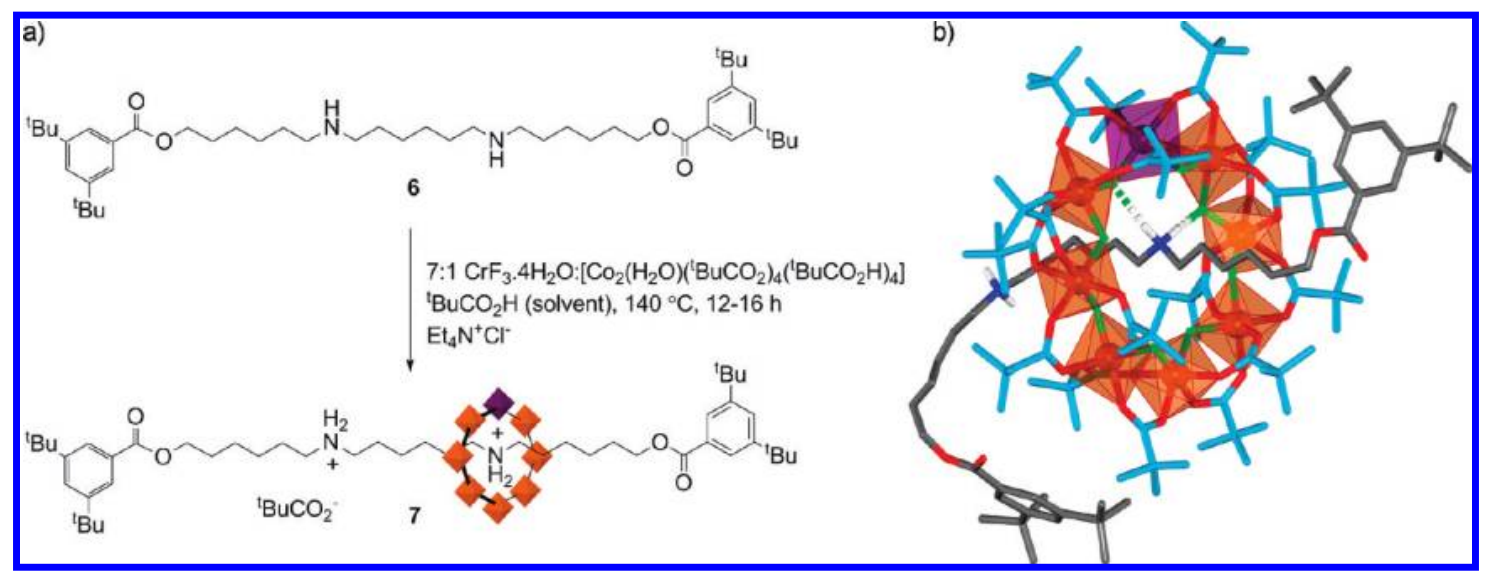

Figure 5. Synthesis (a) and X-ray structure (b) of molecular shuttle 7. Atom coloring is as indicated in the Figure 1 caption. The divalent metal ion, Co(II), is disordered over the eight metal sites on each heterometallic wheel. Crystallographic data and experimental details of the structural refinement for $\mathbf{7}$ are provided in the Supporting Information.

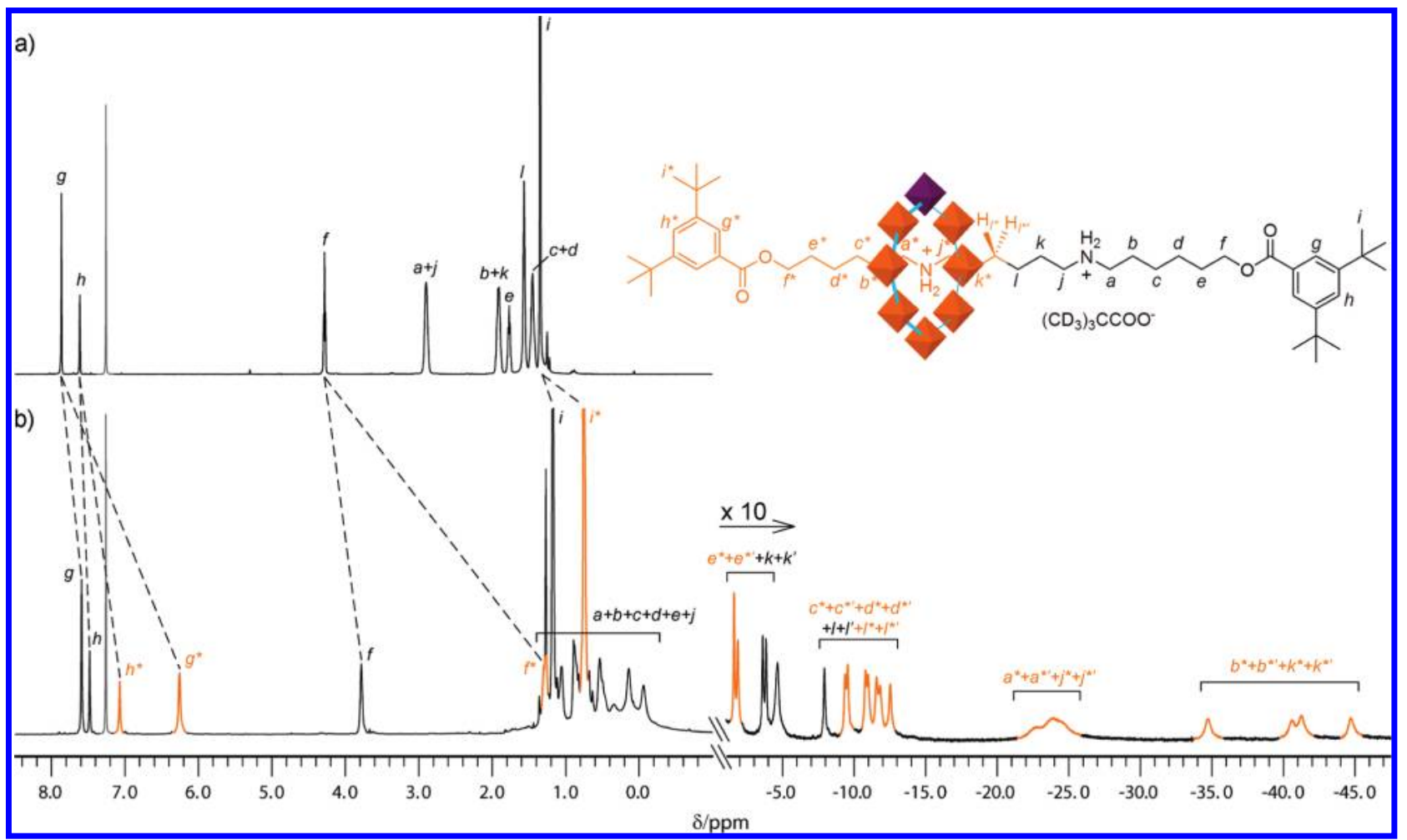

Figure 6. ${ }^{1} \mathrm{H}$ NMR spectra ( $500 \mathrm{MHz}, \mathrm{CDCl}_{3}, 298 \mathrm{~K}$ ): (a) Thread $6 \cdot 2 \mathrm{PF}_{6}{ }^{-}$, (b) [2]rotaxane molecular shuttle $d_{144}{ }^{-7}$. The signals labeled $*$ shown in orange in spectrum (b) belong to the protons of the half thread where the ring is located. Signals labeled ' are parts of sets of diastereotopic protons. Per-deuterating the pivalate methyl groups facilitates characterization of the relatively low intensity thread protons in the rotaxane (spectrum (b)). The rotaxane signals below $-1 \mathrm{ppm}$ are shown at $10 \times$ magnification and on a compacted $X$-axis compared to the signals above $-1 \mathrm{ppm}$. Residual solvent peaks and impurities are shown in gray.

hydrogen bonding in the solid state structures of [2]rotaxanes $\mathbf{4 a}-\mathbf{d}, \mathbf{4 f}$, and $\mathbf{4 g}$ is reminiscent of the bifurcated $\mathrm{F}^{-} \cdot \cdots \mathrm{HN}^{+}$ interactions between four bridging fluoride ligands and the thread ammonium group seen in $\mathrm{Cr}_{7} \mathrm{Fe}$-pseudorotaxane $\mathbf{2 f}$ (Figure 1f). The intercomponent hydrogen bonding in $\mathrm{Cr}_{7} \mathrm{Cu}$ [2] rotaxane $4 \mathbf{e}$ (Figure 4f) is similar to the linear F $\cdots H N$ hydrogen bonds seen in the crystal structures of the other rotaxanes in Figure 1.

$\mathrm{Cr}_{7} \mathrm{Co}$-[2]rotaxane (4a) and $\mathrm{Cr}_{7} \mathrm{Fe}$-[2]rotaxane (4c) were also characterized in $\mathrm{CDCl}_{3}$ solution by ${ }^{1} \mathrm{H} \mathrm{NMR}$ spectroscopy (see Supporting Information). The Fe(II) ions have a relatively slow rate of nuclear relaxation, counterbalancing the fast electronic relaxation of $\mathrm{Cr}(\mathrm{III})^{18}$ in a similar way to $\mathrm{Co}$ (II) (Figure 2), but with greater line broadening and more modest paramagnetic shifts leading to less well-resolved spectra. As with rotaxane $\mathbf{2 a}$, only eight resonances for the pivalate groups are observed in both $\mathbf{4 a}$ and $\mathbf{4} \mathbf{c}$ indicating rapid rotation of the ring on the NMR time scale.

A Hybrid Organic-Inorganic Molecular Shuttle. The hybrid organic-inorganic rotaxane synthesis was successfully extended to higher architectures (the assembly of [3]- and [4]rotaxanes has been reported elsewhere ${ }^{4}$ ) including threads containing two

(18) Glass, M. M.; Belmore, K.; Vincent, J. B. Polvhedron 1993, 12, $133-$ 140. 


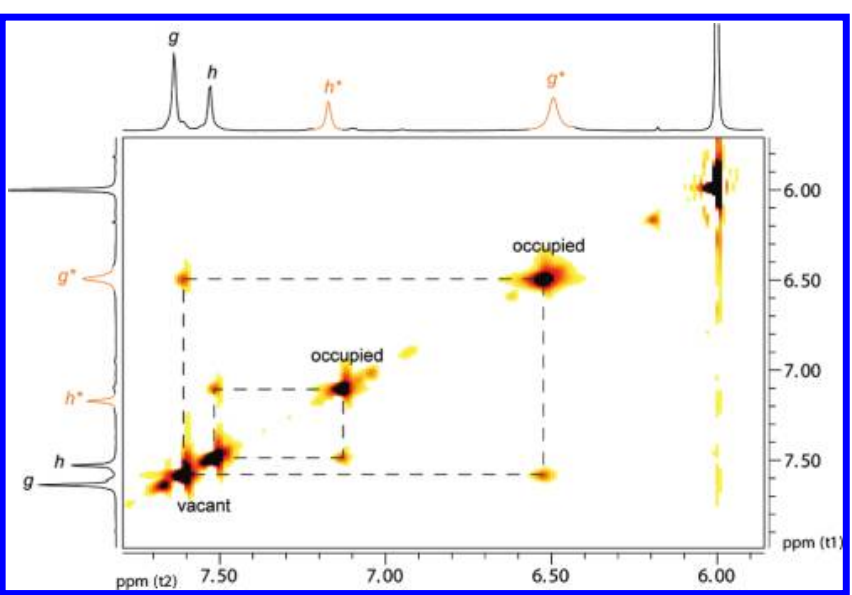

Figure 7. Partial 2D-EXSY spectrum of $d_{144}-7\left(500 \mathrm{MHz}, \mathrm{C}_{2} \mathrm{D}_{2} \mathrm{Cl}_{4}, 330\right.$ $\left.\mathrm{K}, \tau_{\mathrm{m}}=50 \mathrm{~ms}\right)$.

ammonium binding sites. Using the bis-amine $\mathbf{6}$ as a thread, [2] rotaxane 7, with one $\mathrm{Cr}_{7} \mathrm{Co}$-heterometallic ring on an axle with six methylene groups between the two ammonium groups, was synthesized (Figure 5). The molecular shuttle 7 could not be prepared without the use of an amine/ammonium additive but was isolated in 36\% yield from a reaction employing tetraethylammonium chloride and could also be obtained in a more modest yield using diethylamine, (chloromethyl)triethyl-

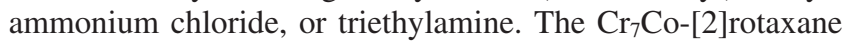
7 was structurally characterized by ESI-MS, X-ray crystallography (Figure 5b), and ${ }^{1} \mathrm{H}$ NMR spectroscopy (Figure 6).

The ${ }^{1} \mathrm{H}$ NMR spectrum of $d_{144-7}$ (the deuterated analogue of 7) in $\mathrm{CDCl}_{3}$ at room temperature shows a well-resolved set of signals for each half of the thread (shown in orange and black in Figure 6); the difference within each set of signals is caused by whether the adjacent ammonium center is vacant or occupied by the heterometallic ring. Remarkably, no line broadening was observed even at $400 \mathrm{~K}$ indicating that the shuttling is slow on the NMR time scale even at those elevated temperatures.

The rate of exchange of the ring between the two binding sites on the thread could be measured by polarization transfer between signal pairs using two-dimensional exchange spectroscopy $\left(\mathrm{EXSY}^{19}\right.$ ) experiments (Figure 7 ). At $330 \mathrm{~K}$ in $\mathrm{C}_{2} \mathrm{D}_{2} \mathrm{Cl}_{4}$, these measurements gave a rate of exchange of $1.2 \pm 0.5 \mathrm{~s}^{-1}$, corresponding to a free energy of activation $\left(\Delta G^{\ddagger}\right)$ of $19.3 \pm$ $0.2 \mathrm{kcal} \mathrm{mol}^{-1}$. This value is at least $10 \mathrm{kcal} \mathrm{mol}^{-1}$ larger than the activation barrier for rotation of the ring around the thread. This notable difference in the rates of the intercomponent dynamics can be rationalized by the nature of the intercomponent $\mathrm{NH}-\mathrm{F}$ hydrogen bonding seen in the various crystal structures. The symmetry of the heterometallic wheels means that a one-eighth turn $\left(45^{\circ}\right)$ is sufficient to the transfer of hydrogen bonds of the ammonium group from one bridging fluoride ion to the next one. Furthermore, a one-sixteenth turn $\left(22.5^{\circ}\right)$ maps the $\mathrm{F}^{-} \cdot \cdot \mathrm{HN}^{+}$hydrogen bonding onto the bifurcated hydrogen bond motif seen in several of the crystal structures (Figures 1f, 4a-e, 4g, 4h) meaning that rotation can occur without significant breaking of an existing hydrogen bond before a new one starts to form (Figure 8b). In contrast, the shuttling requires complete breaking of all the intercomponent $\mathrm{NH}-\mathrm{F}$ hydrogen bonds before translocation can occur, resulting in a much slower process.

\section{Conclusions}

Kinetically stable hybrid organic-inorganic rotaxanes and molecular shuttles have been prepared through template syn-

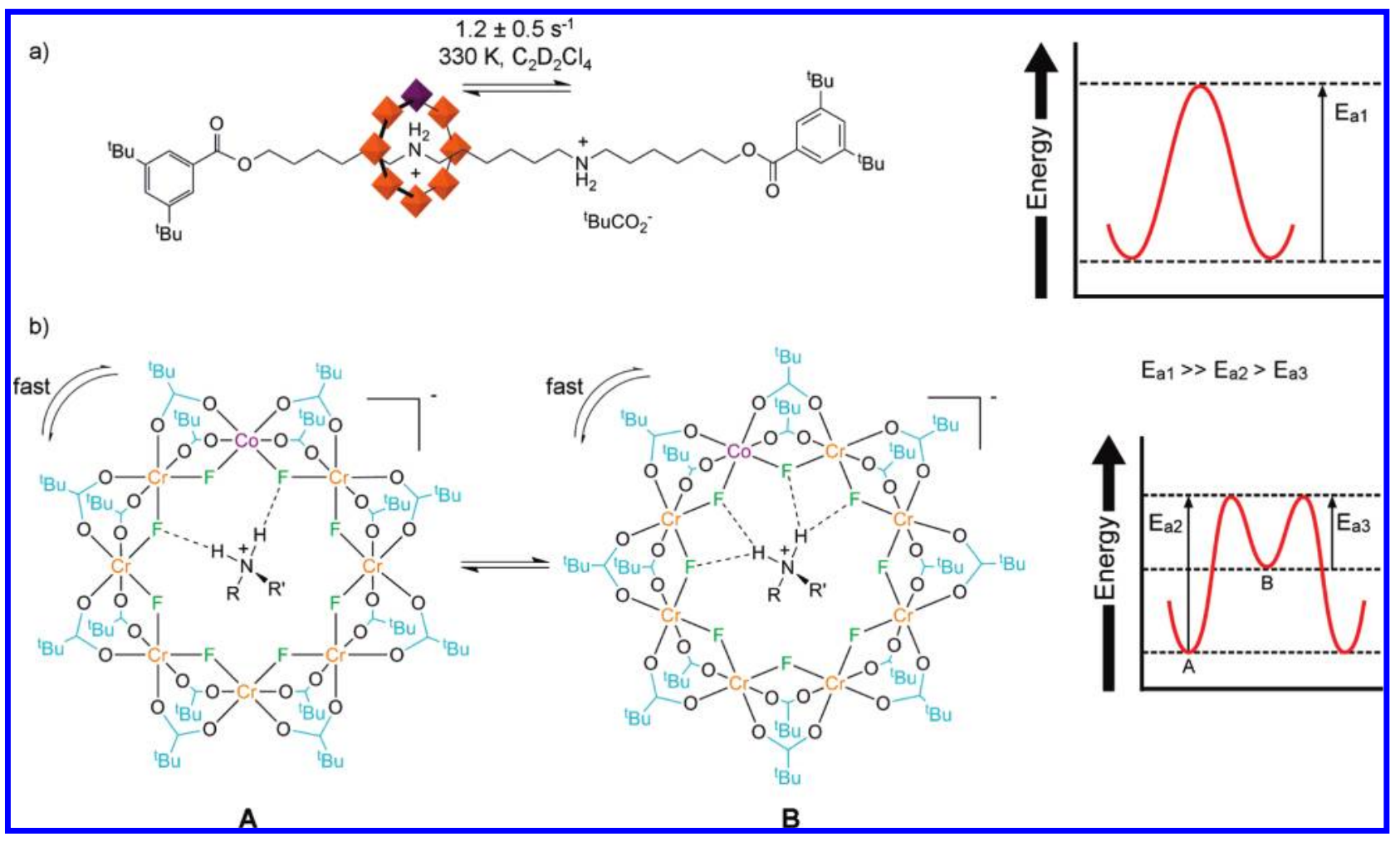

Figure 8. (a) Energy profile for shuttling. (b) Energy profile for rotation. A low energy route for rotation of the heterometallic ring about the ammonium group could involve the system passing through two different types of hydrogen bonded state (A and B). In A, each proton of the ammonium station point is involved in one linear ${ }^{+} \mathrm{NH} \cdots \mathrm{F}^{-}$hydrogen bond with one fluoride atom of the ring. In $\mathrm{B}$, each proton of the ammonium station forms bifurcated $\mathrm{H}$-bonds with two fluorides of the ring. Both types of hydrogen bond motif are seen in the X-ray crystal structures of various rotaxanes (Figures 1 and 4). 
thesis in yields that range from $5 \%$ to $92 \%$. Some of the factors controlling the efficiency of the rotaxane synthesis have been identified, and improved protocols, including the use of additives and a one-pot 'stoppering-plus-macrocyclization' strategy, have been introduced, efficiently generating rotaxanes with a range of different divalent transition metal ions (Co(II), Ni(II), Fe(II), $\mathrm{Mn}(\mathrm{II}), \mathrm{Cu}(\mathrm{II}), \mathrm{Zn}(\mathrm{II})$, and $\mathrm{Cd}(\mathrm{II}))$. In a rotaxane with a free ammonium site on the thread - molecular shuttle 7 - rotational dynamics (of the ring spinning around the thread) are much faster than translational dynamics (the ring moving between ammonium sites on the thread) because of the nature of the intercomponent hydrogen bonding interactions. Hybrid organicinorganic rotaxanes constitute promising candidates for molecular machines that combine some of the features of the chemistry of inorganic clusters (magnetism, electronic properties) with the dynamic properties typical of organic-based interlocked molecules. $^{4 \mathrm{~b}}$ Such systems may prove useful in helping to establish how heterometallic-ring-based qubits can be linked to maximize entanglement of spins without inducing decoherence. Furthermore, the ability to move qubits with respect to one another under the action of an external stimulus could potentially be used to produce arrays where the qubits are close, allowing one

(19) Perrin, C. L.; Dwyer, T. J. Chem. Rev. 1990, 90, 935-967. type of algorithm to be implemented (an "on" position), or more distant, which could be regarded as a system being on "standby". Much remains to be done before such hypothetical devices can be constructed, in terms of both controlling intercomponent motion and learning how to measure, control, and utilize very weak through-space magnetic interactions.

Acknowledgment. We thank Juraj Bella for the EXSY NMR experiments and the EPSRC National Mass Spectrometry Service Centre (Swansea, U.K.) for high resolution mass spectrometry. This research was funded by the European Commission (through the NoE 'MAGMANet') and the EPSRC. The Advanced Light Source is supported by the Director, Office of Science, Office of Basic Energy Sciences, of the U.S. Department of Energy under Contract No. DE-AC02-05CH11231. We are grateful to the Swiss National Science Foundation for a postdoctoral fellowship to D.S. and the Ministerio de Ciencia e Innovación for a postdoctoral fellowship to B.B. D.A.L. is an EPSRC Senior Research Fellow. R.E.P.W. and D.A.L. hold Royal Society-Wolfson Research Merit Awards.

Supporting Information Available: Experimental procedures and the supplementary crystallographic data. This material is available free of charge via the Internet at http://pubs.acs.org.

JA1074773 